\title{
Dynamic Recovery and Recrystallization in an Iron-Containing Aluminium Bronze
}

\author{
By A. Q. Khan*
}

\begin{abstract}
The effect of three different rolling temperatures on dynamic recovery and recrystallization in an iron-containing copper-aluminium alloy has been evaluated. Rolling at about $980^{\circ} \mathrm{C}$ in the $\beta$ phase field results in dynamic recrystallization and fine-grained material is obtained. Iron particles precipitated during rolling inhibit grain growth. By rolling the material at 800 and $650^{\circ} \mathrm{C}$, where the structure consists of $(\alpha+\beta)$ phases, elongated fibrous crystals are obtained. The dynamic recovery at these temperatures is so remarkable that subsequent high temperature annealing does not induce any recrystallization, but annealing for longer periods of time results first in some 'perfection' of the sub-structure and later also of the grains, and the fibrous structure disappears.
\end{abstract}

(Received May 13, 1973)

\section{Introduction}

Deformation at high temperatures is coupled with thermally activated softening which controls the magnitude of the stress level required during the deformation process and also the microstructure obtained in the subsequent deformed material. Two main softening processes involved in deformation at elevated temperatures are: (1) dynamic recovery and (2) dynamic recrystallization. Considerable amount of literature is available on dynamic recovery which is now well understood and which takes place in the original grains of the material predominantly as a result of annihilation and re-arrangement of dislocations and the migration of vacancies, etc. The dislocation substructures associated with the recovery process have been widely studied in the last two decades, especially in connection with creep studies at high temperatures.

When a material is plastically deformed, dislocation multiplication takes place due to the presence of dislocation sources, but in spite of the continuous generation of dislocations, the dislocation density does not reach a maximum limiting value which the metallic lattice can contain. At elevated temperatures the annihilation process begins to dominate the multiplication process when the dislocation density is high. Since these processes take place during deformation, they are called 'dynamic'. The annihilation processes control the maximum value of the dislocation density at high degrees of plastic deformation.

During the dynamic recovery the dislocations leave their original slip plane to facilitate the annihilation with dislocations of opposite sign or take up an energetically more stable position. This happens by crossslip in the case of screw dislocations and by climb with edge dislocations. If recrystallization takes place, the defect lattice with a high dislocation density obtained during deformation is transformed into an undistorted lattice.

* Materials Engineering Department, FDO Technical Advisors, P.O. Box 379, Amsterdam, Holland.

Trans. JIM
Since both the dynamic recovery and dynamic recrystallization processes are thermally activated, the temperature, strain rate and the degree of deformation are the most important controlling factors. A number of theories ${ }^{(1) \sim(6)}$ on the mechanism of hot working and dynamic recovery and recrystallization have been formulated. According to Sellers and Tegart ${ }^{(1)}$ dynamic recovery plays a significant role in deformation at elevated temperatures and seems to be the rate controlling mechanism in aluminium; however, recrystallization could be the rate controlling mechanism in metals and alloys of low stacking fault energy, such as copper, nickel and their alloys. Stüwe ${ }^{(2)}$ has suggested a mechanism of high temperature deformation in which the climb of edge dislocation into sub-grain boundaries and their annihilation has been conceived. Detailed work by Jonas, McQueen and Wong ${ }^{(3) \sim(6)}$ has thrown light on the inter-relationship between deformation parameters and the substructures in the extrusion of aluminium. There are some excellent reviews on the subject of which only four are cited ${ }^{(7) \sim(10)}$.

In the present study an iron-containing $\beta$ aluminium bronze was rolled to about $80 \%$ reduction at three different temperatures and the resulting macro- and microstructures were examined by optical microscopy. The materials were then annealed at high temperature for long periods of time to assess the influence of this annealing on recrystallization and grain growth. This study which formed part of a detailed investigation of the effect of morphology on the strength of copperbased martensites ${ }^{(11) \sim(15)}$ is not virtually a quantitative work but can be considered valuable as it points out the possibility of a detailed quantitative study in a direction which is of great commercial interest.

\section{Experimental Procedure}

The material, $\mathrm{Cu}-11 \mathrm{wt} \% \mathrm{Al}-3 \mathrm{wt} \% \mathrm{Fe}$, was prepared from electrolytic copper, $99.99 \%$ pure $\mathrm{Al}$ and pure Armco iron. All the metals were melted in vacuum by an induction furnace and cast into a permanent mould in the shape of a block measuring about $8 \mathrm{~cm} \times 8 \mathrm{~cm} \times 4 \mathrm{~cm}$ and furnace cooled. Chemical and

1974 Vol. 15 
$\mathrm{X}$-ray fluorescence analyses gave the composition as $\mathrm{Cu}-11.15 \mathrm{wt} \% \mathrm{Al}-2.85 \mathrm{wt} \% \mathrm{Fe}$.

The ingot was homogenized for $5 \mathrm{hr}$ at $1000^{\circ} \mathrm{C}$ and then sawn into 4 slices, each measuring about $8 \mathrm{~cm} \times$ $8 \mathrm{~cm} \times 1 \mathrm{~cm}$. One of the slices was kept apart for macroscopic examination. The remaining 3 slices were subjected to hot rolling at $980^{\circ} \mathrm{C}(\beta$ phase field $)$, $800^{\circ} \mathrm{C}\left(\alpha+\beta / \beta\right.$ phase boundary) or $650^{\circ} \mathrm{C}(\alpha+\beta$ phase field) and then quenched into water. The rolling reduction was about $80 \%$.

Specimens measuring $1 \mathrm{~cm} \times 1 \mathrm{~cm} \times 0.15 \mathrm{~cm}$ prepared from the 3 hot-rolled materials were annealed at $1000^{\circ} \mathrm{C}$. All the heat treatments were carried out in a vertical furnace and the specimens were then dropped into iced brine; the annealing time extended from $\frac{1}{2} \mathrm{hr}$ to $5 \mathrm{hr}$. This was done to assess the tendency of the material towards grain growth.
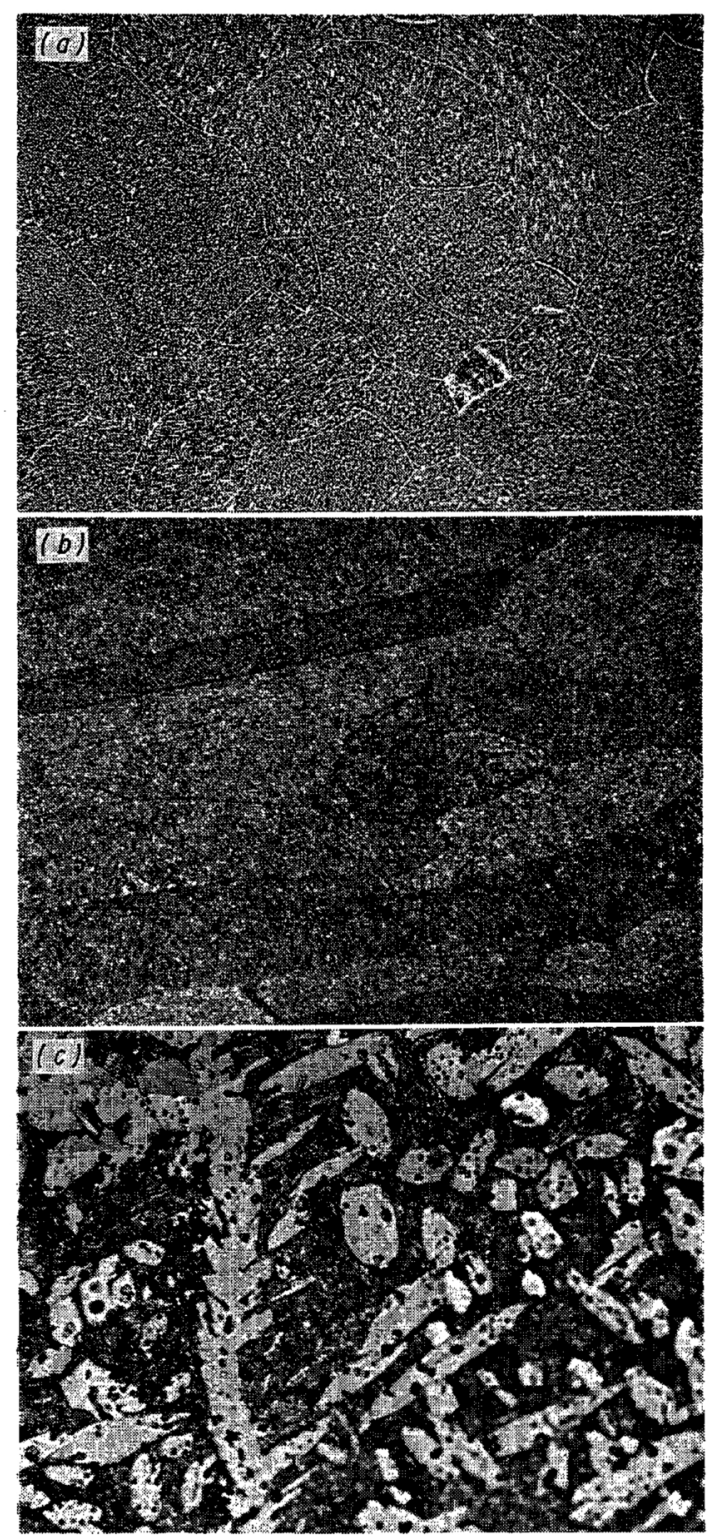

Photo. 1 Cast structure of $\mathrm{Cu}-\mathrm{Al}-\mathrm{Fe}$ alloy; (a) central part of the ingot $(\times 10),(b)$ at the periphery ( $\times 25)$, (c) magnified $(\times 200),-\alpha$ (white) in a pearlitic $\left(\alpha+\gamma_{2}\right)$ matrix. Black spots are ironrich precipitates.

\section{Results}

(1) As-cast structure: The as-cast structure was found to be coarse with equi-axed grains of about $3 \mathrm{~mm}$ diameter in a small central zone and columnar grains, 2 to $3 \mathrm{~cm}$ long and 0.3 to $0.4 \mathrm{~cm}$ wide, extending from the centre towards the periphery, Photo. 1.

(2) As-rolled structure: There was a considerable difference in grain size of the material after hot rolling at 980,800 and $650^{\circ} \mathrm{C}$, Photos. 2, 3 and 4. The material rolled at 650 and $800^{\circ} \mathrm{C}$ showed coarse elongated grains throughout the specimens with the coarser grains at $650^{\circ} \mathrm{C}$. In contrast to these specimens, the material rolled at $980^{\circ} \mathrm{C}$ had comparatively much finer equi-axed grains.

(3) Material rolled at $980^{\circ} \mathrm{C}$, annealed at $1000^{\circ} \mathrm{C}$ and quenched into water: Annealing up to $2 \mathrm{hr}$ did not greatly influence the grain size and the grains looked very similar to those in the rolled structure except that some 'straightening' of the boundary curvature was noticeable, Photo. 5. Grain growth was observed only with the annealing time exceeding $2 \mathrm{hr}$. After about $5 \mathrm{hr}$ the grains grew twice and thrice its original size. The martensitic structure seen in Photo. 5(b) and in other photographs is obtained as a result of phase transformation whereby the high temperature $b c c \beta$ phase is transformed, upon rapid cooling, to an ordered orthorhombic close-packed structure, $\beta^{\prime(14)}$.

(4) Material rolled at $800^{\circ} \mathrm{C}$, annealed at $1000^{\circ} \mathrm{C}$ and quenched into water: The grain size was slightly larger than the one observed in the material rolled at

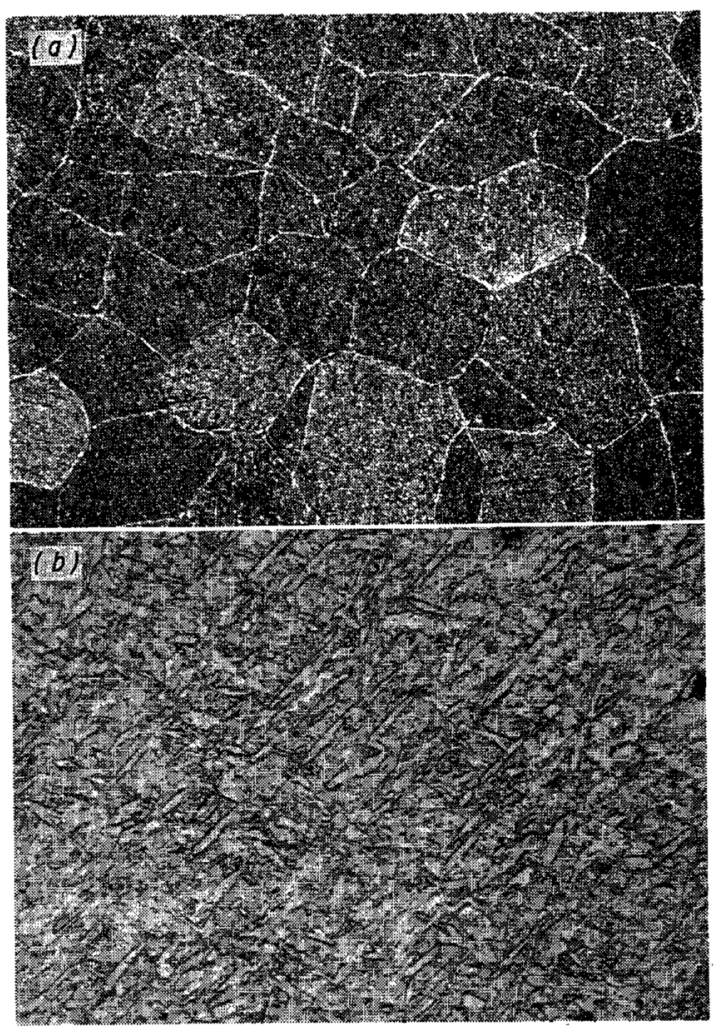

Photo. 2 Material rolled at $980^{\circ} \mathrm{C}$. (a) shows crystal size and morphology $(\times 50)$ and (b) the matrix structure $(\times 200)$. 

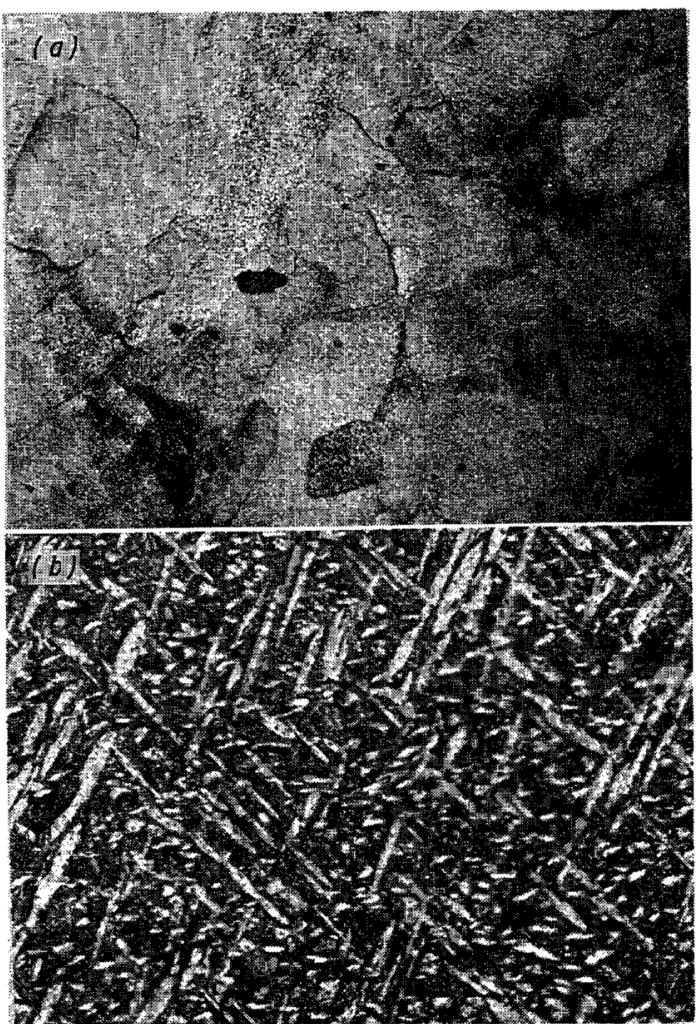

Photo. 3 Material rolled at $800^{\circ} \mathrm{C}$. The structure is somewhat similar to that in Photo. 2 but (a) the grains are slightly coarser $(\times 20)$, and (b) the matrix contains a higher percentage of $\alpha(\times 200)$.
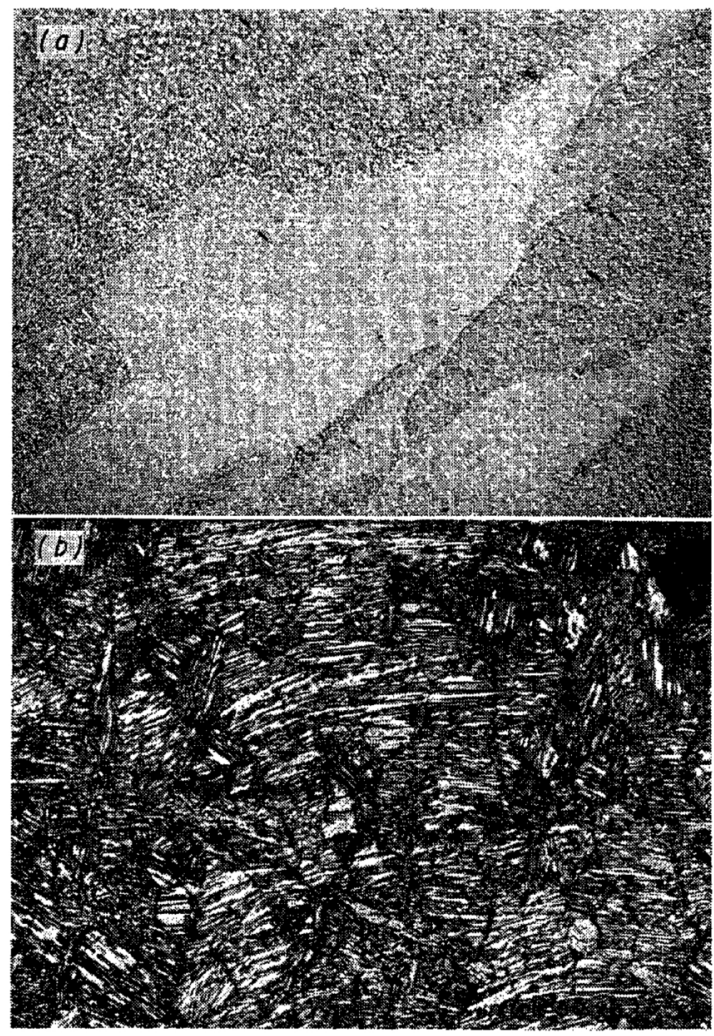

Photo. 4 Material rolled at $650^{\circ} \mathrm{C}$. The structure consists of (a) elongated coarse grains $(\times 10)$, with (b) the low-temperature $\alpha$ phase spread between the $\beta$ grains in the rolling direction $(\times 200)$.
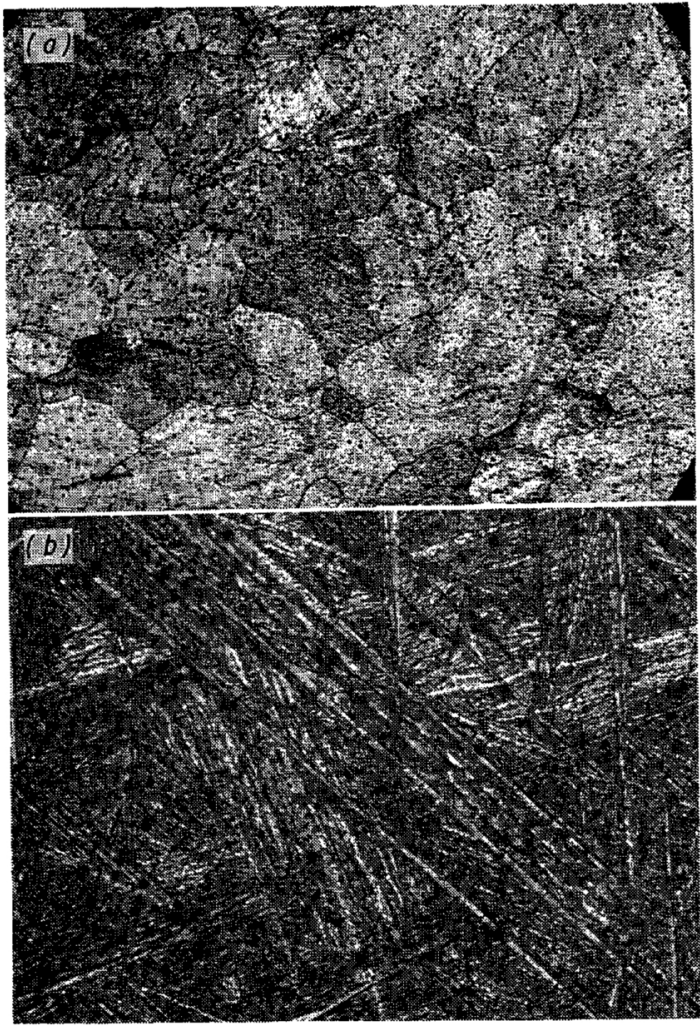

Photo. 5 Material rolled at $980^{\circ} \mathrm{C}$ and annealed at $1000^{\circ} \mathrm{C}$ for $1 / 2 \mathrm{hr}$. The structure consists of (a) equi-axed grains $(\times 100)$, with (b) the matrix structure being martensitic $(\times 1200)$.

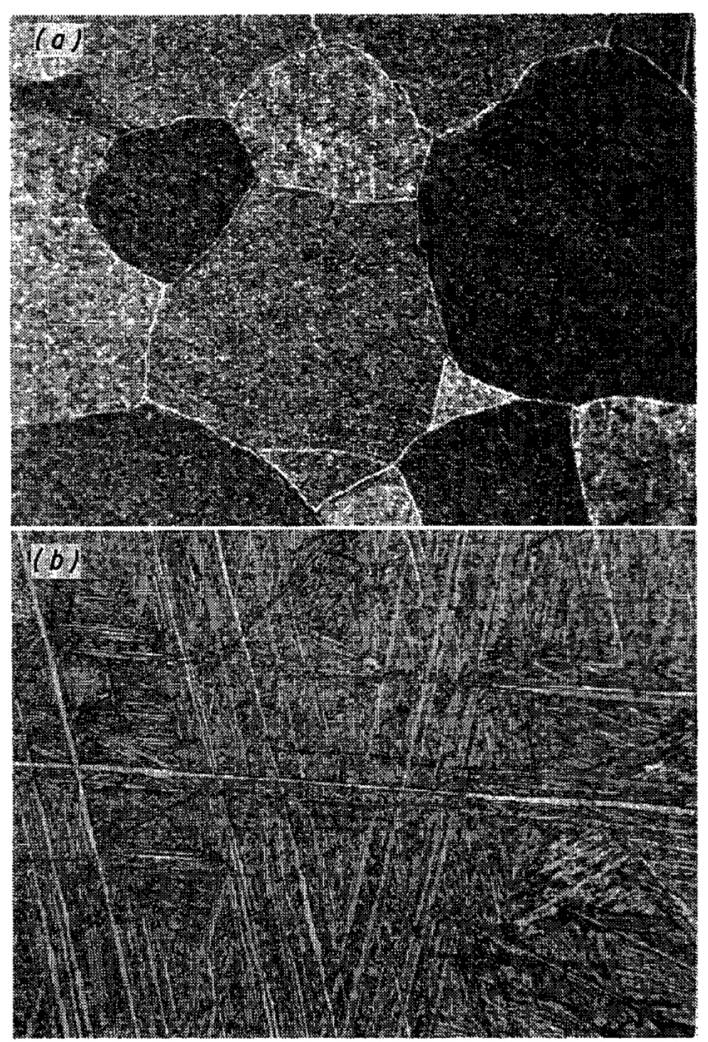

Photo. 6 Material rolled at $800^{\circ} \mathrm{C}$ and annealed at $1000^{\circ} \mathrm{C}$ for $1 / 2 \mathrm{hr}$. The structure consists of (a) regularly shaped coarse grains $(\times 200)$, and (b) the matrix is martensitic $(\times 630)$. 

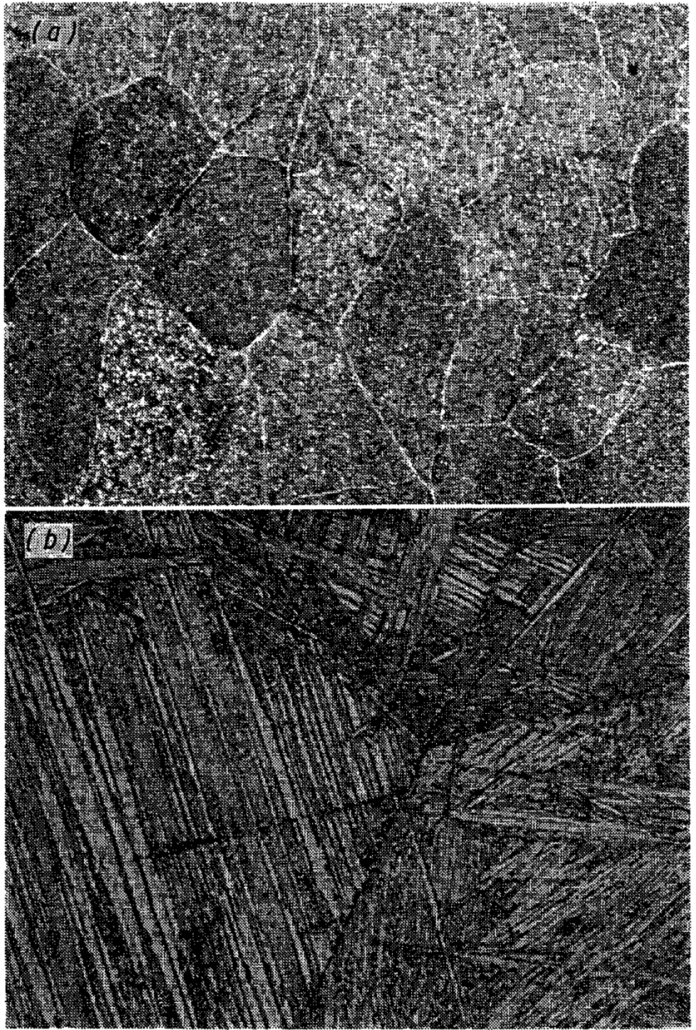

Photo. 7 Material rolled at $650^{\circ} \mathrm{C}$ and annealed at $1000^{\circ} \mathrm{C}$ for $1 / 2 \mathrm{hr}$. The structure consists of (a) elongated crystals $(\times 20)$, and (b) the matrix is martensitic $(\times 200)$.

$980^{\circ} \mathrm{C}$ and annealed for the same period of time. On annealing for a longer period of time, $5 \mathrm{hr}$, there was an abrupt grain growth after about $2 \mathrm{hr}$. Thus the behaviour was similar to the material rolled at $980^{\circ} \mathrm{C}$ with the exception that the grains in this case were somewhat larger, Photo. 6.

(5) Material rolled at $650^{\circ} \mathrm{C}$, annealed at $1000^{\circ} \mathrm{C}$ and quenched into water: All the specimens showed coarse grains regardless of whether they were annealed for a short or long period of time. Long period annealing did, however, eliminate the typical fibrous structure and crystals appeared more or less equi-axed but still a bit elongated in the rolling direction. Compared with the material rolled at 980 and $800^{\circ} \mathrm{C}$ and with identical heat treatments, these specimens showed much coarser and elongated grains, Photo. 7.

\section{Discussion}

Notwithstanding that this investigation is not quantitative it can be pointed out for general information that in normalized fine-grain steels the refinement of the austenite grain size is usually achieved by grain boundary pinning due to fine second phase particles. Gladman and Pickering ${ }^{(16)}$ have studied in detail the grain-coarsening behaviour of steels containing second phase particles and formulated an equation given as:

$$
r^{\circ}=\left(6 R_{0} f / \pi\right)(3 / 2-2 / z)^{-1}
$$

where $r^{\circ}=$ critical particle radius for pinning 'austenite' grain boundaries,

$R_{0}=$ matrix or austenite grain size,

$f=$ volume fraction of the second phase particles,

$z=$ ratio of radii of growing and matrix grains or matrix heterogeneity $=$ ca. 1.5 .

The same equation can generally be applied to other metals and alloys containing second phase particles.

The processes of dynamic recovery and recrystallization during rolling can be explained in the following way. At high temperatures (ca. $980^{\circ} \mathrm{C}$ ) the $\beta$ phase is very soft and more ductile than the $\alpha$ phase ${ }^{(17)}$. Hot rolling is expected to result in a more or less homogeneous deformation of the material containing the $\beta$ phase only and no stress concentration gradients are expected. This is of course different from room or low temperature deformation where neither stress nor strain is uniform in differently oriented crystals and deformation is anisotropic in a polycrystalline aggregate. The $\beta$ grain boundaries, which are regions of distorted lattice extending over a few atomic distances, cause abrupt crystallographic orientation changes between adjoining grains resulting in discontinuities at the boundaries during plastic deformation. The requirement for continuity between grains during plastic deformation introduces rather complex modes of deformation within the individual grains and slip on multiple systems takes place in polycrystalline aggregates. During high temperature deformation, discontinuities at grain boundaries are, however, limited to a minimum because of the 'transparency' of grain boundaries to dislocation migration and also possibly due to the availability of more slip modes for easy continuity between grains. Since large deformations (ca. $80 \%$ reduction) are effected in our case and the temperature is quite high, there is most probably a spontaneous and more or less homogeneous recrystallization throughout the material resulting in a large number of new defect-free crystals. The absence of any slip lines later on the polished surface confirms the existence of the recrystallized structure. Under normal circumstances, when no foreign atoms or precipitates are present, one would expect the matrix to be swept clean by the movement of the newly-formed grain boundaries at this high temperature. However, in this case the finely dispersed iron particles significantly influence the grain boundary mobility and directly obstruct its motion. The rolling at relatively lower temperatures $\left(800\right.$ and $\left.650^{\circ} \mathrm{C}\right)$ consists of deformation of a material containing a second phase $\alpha$. At $800^{\circ} \mathrm{C}$, the amount of $\alpha$ is not too much (ca. $25 \%$ ), but at $650^{\circ} \mathrm{C}$ this amount is substantial (ca. $45-50 \%$ ) and the rolling is done on a two-phase material in both the cases. At the lower temperature the $\alpha$ phase is more ductile than the $\beta$ phase and rolling results in a fibrous structure with $\alpha$ spread between $\beta$ grains in the rolling direction. The presence of duplex structure, in our opinion, is responsible for mechanically induced high stress concentrations. Even though rolling at low temperature is expected to cause a high rate of work hardening, the temperature is just too low to cause any recrystallization. There is probably a good deal of 
recovery but no new grains on a substantial scale are formed. This is consistent with the observed phenomena that dynamic recovery is faster in $f c c$ materials than in $b c c$ or $h c p$ metals and alloys or in materials with low stacking fault energy ${ }^{(10)(18)}$. Thus the material rolled at 800 and $650^{\circ} \mathrm{C}$ (in reality the temperatures are lower due to the transferring of the material from the furnace to the rolls and also due to the contact of the material with cold rolls before the actual deformation takes place) contained a high percentage of $f c c \alpha$ and recovered dynamically much faster than the alloy consisting of the $\beta$ phase only. Still the material rolled at $800^{\circ} \mathrm{C}$ is more uniformly and homogeneously deformed than the one at $650^{\circ} \mathrm{C}$. Thus annealing the material at high temperatures $\left(\mathrm{ca} .1000^{\circ} \mathrm{C}\right.$ ) results in grain boundary migration of the already existing deformed grains and probably in nucleation of a very few grains, more so in the material rolled at $800^{\circ} \mathrm{C}$. These observations are consistent with the experimental facts reported by other workers ${ }^{(7)(8)}$.

The influence of annealing time on grain growth could be explained in the following way. In the completely recrystallized material, the driving force for further grain growth (during prolonged annealing) lies in the surface energy of the grain boundaries. As the grains grow in size and their number decreases, the grain boundary area diminishes and the total surface energy is lowered accordingly ${ }^{(19)}$. As isothermal annealing progresses, the grain size increases (within certain limits) and while growth proceeds the grains become more perfect due to annihilation and elimination of defects. In both the recovery and recrystallization processes, long time isothermal annealing causes the sub-structure to become more and more perfect, with the result that the rolled structure also becomes somewhat more equi-axial in appearance and the fibrous outlook disappears. This observation is, as a matter of fact, consistent with the experimental results of Berghèzan ${ }^{(20)}$ who observed similar process taking place in rolled $\mathrm{Al}-3 \% \mathrm{Mg}$ alloys.

It is thus interesting to remember that the important parameter in the recovery and recrystallization processes during hot working of two-phase alloys is the deformation structure, i.e. the type, density and configuration of dislocations in both the phases and the ratio in which both these phases are present. The nature of the deformed structure itself is controlled by the different mechanical properties of the two different phases. It is thus influenced by the degree of deformation and by the volume fractions and grain size of individual phases.

\section{Conclusions}

On the basis of the experimental results and discussion described in the preceding sections, the following conclusions have been drawn:

(1) In copper-aluminium $\beta$-type alloy containing $3 \%$ iron, rolling at about $980^{\circ} \mathrm{C}$ in the $\beta$ phase field results in dynamic recrystallization and fine-grained material is obtained. Iron particles are precipitated during rolling and inhibit grain growth. Annealing at about $1000^{\circ} \mathrm{C}$ for up to $2 \mathrm{hr}$ does not influence the grain size, but further annealing results in elimination of the pinning effect of iron-rich particles and abrupt grain growth occurs.

(2) Rolling the material at 800 and $650^{\circ} \mathrm{C}$ where the structure consists of $\alpha+\beta$, deformation is carried on a two-phase alloy. The low temperature rolling produces elongated, fibrous grains and the dynamic recovery is so great that subsequent high temperature annealing does not induce any recrystallization. Annealing for longer periods of time results in some 'perfection' of the sub-structure and subsequently of the grains, and the fibrous look disappears. If the annealing time is extended beyond $2 \mathrm{hr}$, abrupt grain growth is observed.

\section{Acknowledgements}

This work was performed at the Department of Metallurgy, Katholieke Universiteit Leuven and the author is thankful to Prof. L. Delaey for his valuable advice and discussions, to Prof. A. Deruyttere for the provision of research facilities, to the Belgian Ministry of National Education (Directorate International Cultural Relations) for the grant of a Research Fellowship and to the Katholieke Universiteit Leuven for financial assistance. He also wishes to express his gratitude to Prof. Dr. W. G. Burgers and Dr. J. van der Planken for valuable comments and suggestions, to Ir. A. Langstraat, Manager, Materials Engineering Department, FDO, for facilities and encouragement to prepare this paper and to the referees for their constructive criticism of the manuscript.

\section{REFERENCES}

(1) C. M. Sellars and W. J. McG. Tegart: Acta Met., 14 (1967), 1136.

(2) H. P. Stüwe: Acta Met., 13 (1965), 1337.

(3) W. A. Wong, H. G. McQueen and J. J. Jonas: J. Inst. Metals, 95 (1967), 129.

(4) J. J. Jonas, J. H. McQueen and W. A. Wong: Deformation under Hot Working Conditions, ISI Publ. No. 108 (1968).

(5) H. J. McQueen, W. A. Won̈g and J. J. Jonas: Can. J. Phys., 45 (1967), 1225.

(6) H. J. McQueen, W. A. Wong and J. J. Jonas: Acta Met., 15 (1967), 586.

(7) J. P. Immarigeon and H. J. McQueen: Canad. Meta. Qrty., 8 (1969), 25.

(8) H. P. Stüwe: Deformation under Hot Working Conditions, ISI Publ. No. 108 (1968).

(9) H. Mecking and F. Kirch: Recrystallization of Metallic Materials, Ed. F. Haessner, Riederer Verlag, Stuttgart (1971).

(10) R. W. K. Honeycombe and R. W. Pethen: Topics in Physical Metallurgy (Burgers Festschrift), Eds. A. Q. Khan and M. J. Brabers, Elsevier (1972); also J. Less-Common Metals, 28 (1972), 201.

(11) A. Q. Khan and L. Delaey: Z. Metallk., 60 (1969), 949.

(12) A. Q. Khan and L. Delaey: Trans. Indian Inst. Metals, T. P. 577 (Dec. 1970).

(13) A. Q. Khan, Dr.-Eng. Thesis: University of Leuven (March 1972).

(14) A. Q. Khan, G. V.d. Perre and L. Delaey: J. Mater. Sci., 7 (1972), 1401. 
(15) L. Delaey, H. Tas and A. Q. Khan: ASM-CDA Conference on Copper, Cleveland, Ohio (Oct. 1972).

(16) T. Gladman and F. B. Pickering: J. Iron Steel Inst. (London), 205 (1967), 653.

(17) P. J. Macken and A. A. Smith: The Aluminium Bronzes, CDA Publ. No. 31 (1966), 77.
(18) J. C. M. Li: Trans. Met. Soc. AIME, 227 (1963), 239.

(19) R. W. Cahn: Physical Metallurgy, Ed. R. W. Cahn, North Holland Publishing Co., Amsterdam (1970).

(20) A. Berghèzan: Métaux, Corrosion, Industries, Nos. 359360 (1955), 1 